\title{
Novos Projetos de Cidadania Biológica: a (re)construção racial dos selves
}

neuroquímicos

Tatiana Rotondaro ${ }^{1}$

Resumo: Este texto tem por objetivo problematizar criticamente as consequências trazidas por uma tentativa discursiva de suplantar a subjetividade humana através da afirmação de uma "individualidade somática", interpretada por perfis genéticos. Essa concepção de indivíduo, juntamente com a influência exercida pela indústria farmacêutica, nos colocaria, segundo Nikolas Rose, diante da emergência de um suposto self neuroquímico, que se expressa numa crescente medicalização da sociedade e acaba por reforçar projetos de 'cidadania biológica'. Tomando como exemplo a discussão em torno da possibilidade de medicalização da raça, encaminho essas reflexões descrevendo o caso do remédio BiDil. Finalmente, abordo brevemente como essa "cidadania biológica" de mercado, num contexto neoliberal, impacta sobre os indivíduos e as coletividades, ou seja, como se rearticulam a tensão de, por um lado, sermos constantemente chamados a nos responsabilizar pelo cuidado de nós mesmos, e por outro, sermos, ao mesmo tempo, compreendidos como arranjos aleatórios de configurações físico-químicas.

Palavras-chave: Biotecnologias; Tecnologia; Corpo; Subjetividade; Teoria Sociológica; Teoria Social

Abstract:This article aims to problematize the consequences brought by a tendency to overcome the human subjectivity through the assertion of a "somatic individuality". This conception of the individual, together with the influence exercised by the pharmaceutical industry, confronts us with the supposed emergency of a neurochemical self. Such explanations are strengthened by an increasing medicalization of society that enhances projects of "biological citizenship". Taking as focus the discussion on the possibility of medicalization of race, I submit these reflections describing the case of the drug BiDil. Finally, I briefly discuss how this "biological citizenship" of market, in a neoliberal context, impacts on individuals and collectivities, that means, how are articulated tensions when, on the one hand, we are constantly called to be responsible for taking care of ourselves, and, on the other, being at the same time, understood as a random arrangement of physical and chemical settings.

Keywords: Biotechnology; Technology; Body; Subjectivity; Sociological Theory; Social Theory
Recebido:

15.09.11

Aprovado:

20.11.12

1. Professora adjunta e coordenadora (pró-tempore) do Programa de Pós-Graduação em Sociologia, da Universidade Federal Fluminense.

E-mail: tatiana.rotondaro@hotmail. com 


\section{Apresentação}

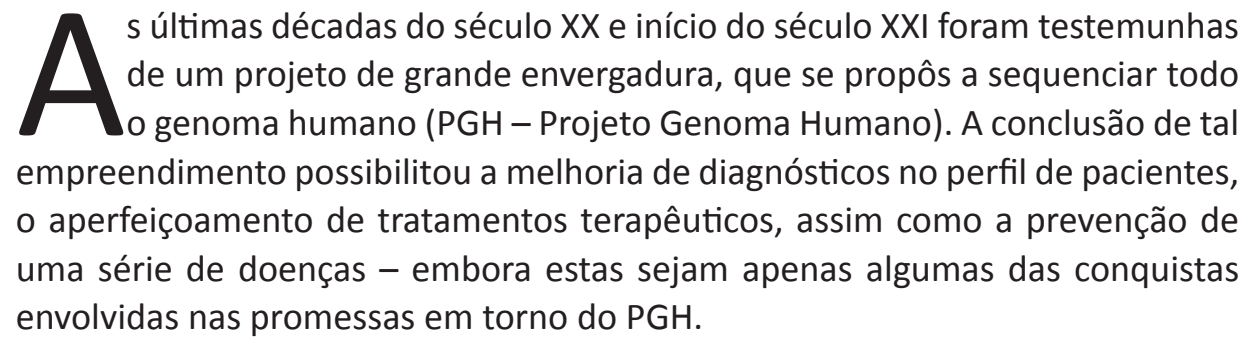

A retórica utilizada por chefes de estado e cientistas para justificar o PGH alicerçava-se na promessa de que os avanços alcançados nas Ciências da vida (na Genética, na Biologia molecular, na Genômica, na Biotecnologia etc.) permitiriam a utilização de técnicas apuradas para a manipulação dos genes, tornando possível compreender, decompor, codificar e traduzir o corpo humano por meio de uma linguagem informacional, capaz de revelar-nos a chave para uma leitura precisa dos aspectos físicos e cognitivos dos seres humanos. De fato, uma releitura mecanicista sobre os condicionantes da ação humana, que tendia a reduzir a vida a um simples objeto material a ser manipulado e estudado, esteve presente em muitos discursos (SANTOS, 2003; MONTEIRO, 2005).

Após o termino do projeto, observou-se certo sentimento de frustração, sobretudo por parte dos investidores mais entusiastas, cujas expectativas de retorno financeiro imediato não foram supridas (JASANOFF, 2005). Nas Ciências Sociais, vozes como de Fox Keller (2002) e Moss (2003), que transitam entre as Ciências Biológicas e Humanas, passaram a ser frequentemente apontadas como sustentação para indicar o fracasso do viés determinista presente na retórica sobre o PGH. Diziam os autores que a grande novidade trazida com a conclusão do Projeto Genoma Humano estava no reconhecimento da complexidade da configuração genética humana (e não humana), bem mais intricada, difícil de ser compreendida do que se supunha e, consequentemente, improvável de pretender-se um tipo de manipulação genética direta e fácil.

Diante desse contexto, qual o sentido de se falar em fármacos específicos para pacientes de determinadas raças (com o BiDil, um medicamento desenvolvido para afro-americanos nos EUA) se o genoma humano aponta inclusive para a impossibilidade, ao menos da forma como havia sido pensada, de se distinguir raças?

Com o intuito de investigar a gênese histórica da metáfora genes-como-texto, que acompanhou todo o processo de construção de legitimidade do PGH, uma vez que este foi apresentado com a promessa de decodificar o "livro da vida", ou o "mapa da vida", a "chave da vida", a "enciclopédia da vida", Lenny Moss 
(2003, p. 17) argumenta que, mesmo em âmbitos mais especializados, em vez de as discussões girarem em torno da realidade empírica alterada pelos genes, frequentemente observamos o contrário, o estabelecimento da metáfora como central para determinar o que é tido como realidade empírica. Assim, afirma o autor: "o idioma da linguagem-do-gene torna-se escrito não por aqueles cujas hipóteses foram bem sucedidas, mas sim por aqueles cujas metáforas foram bem sucedidas". Nesse sentido, a manutenção social dessas "metáforas bem sucedidas" acabou por legitimar um pano de fundo ideológico que mantém o conteúdo mecanicista nas práticas discursivas, ainda que estas tenham sido suplantadas empiricamente. Tais práticas discursivas servem aos propósitos mercadológicos apresentados nas promessas e iniciativas econômicas de segmentos da área médica e de alimentos, que se dedicam à produção de produtos biotecnológicos. Disso decorre, conforme pretendo argumentar nesse artigo, uma série de estratégias, sobretudo, de Estado e mercado, que pretendem explicar toda a complexidade envolvida no funcionamento da vida humana como produto aleatório de combinações físico-químicas que podem ser tratadas a partir de fármacos específicos, de forma a diminuir a importância das interações advindas da relação indivíduo (biológico, psicológico, cultural e social) e ambiente.

\section{O caso da indústria farmacêutica e as Fontes dos Selves Neuroquímicos}

Dedicado ao estudo da atuação das indústrias farmacêuticas, como uma das diversas estratégias mercadológicas de produtos biotecnológicos, que se dizem mais eficazes em função de um melhor conhecimento do funcionamento genético do corpo humano, Nikolas Rose (2003) indica-nos que os mecanismos presentes nessa tentativa de suplantar ou substituir a subjetividade por aspectos físicos pode ser compreendido pela afirmação de uma "individualidade somática".

\footnotetext{
Ser um indivíduo somático nesse sentido é codificar as esperanças e os medos em termos deste corpo biomédico e tentar reformar, curar e aperfeiçoar alguém agindo sobre esse corpo. Este espectro se apresenta numa ponta pelas modificações no 'corpo visível' através de dietas, exercícios, tatuagens, etc., e na outra ponta pelo remodelamento do funcionamento orgânico interior do corpo, usualmente através de intervenções farmacológicas. (ROSE, 2003, p. 54)
}

Juntamente com essa concepção de indivíduo somático, profundamente influenciada pela indústria farmacêutica, emerge com proeminência outra forma de compreender o humano contemporaneamente, a qual Rose (2003) tem chamado de selves neuroquímicos. Algumas das consequências desse processo 
referem-se ao crescente consenso em torno da ideia de que doenças como "depressão", "desordem de ansiedade generalizada", "transtorno de deficit de atenção e hiperatividade (TDAH)" ou até mesmo mudanças de humor que ocorrem na última semana do ciclo menstrual feminino (também conhecidas como "desordem disfórica pré-menstrual") são causadas por uma disfunção química no cérebro, que pode ser tratada por meio da utilização de drogas que poderiam "re-equilibrar" esse desajuste químico. De acordo com os argumentos do autor, essas estratégias das indústrias farmacêuticas não apenas remodelam nossa forma de pensar e agir sobre as desordens do pensamento, do humor e da conduta, como também acarretam significativas consequências para a forma como a Psicanálise e a Psiquiatria são praticadas, pois os distúrbios de fundo emocional apresentam-se, talvez precipitadamente, como tratáveis por meio de um re-equilíbrio físico-químico (ROUDINESCO, 2009). De fato, nesse contexto, preocupações acerca das causas de um determinado estado do humano tendem a ser minimizadas, em contraposição à maximização da objetividade ao eliminar um sintoma supostamente indesejável. Rose chega a ponto de classificar essas nossas sociedades ocidentais que se dedicam à rotinização da prática de modificação de pensamentos, humores e conduta por meio de produtos farmacológicos, de sociedades "psicofarmacológicas", às quais correspondem novos projetos de "cidadania biológica" - conforme veremos um pouco mais adiante. Em função da explícita influência foucaultiana na forma de pensar a relação entre a prática médica e a sociedade, Rose conclui que a racionalidade presente na consolidação desse modelo para lidar e compreender os indivíduos também perpassa a dinâmica de outras instituições sociais, como os locais de trabalho, a escola, a família, as práticas esportivas etc..

Disso decorre que, à medida que essa racionalidade penetra nas instituições sociais, assistimos também a alterações tanto na maneira como compreendemos a ação humana, como nas possibilidades de atuação desse indivíduo no mundo. Nessas sociedades "psicofarmacológicas", as capacidades subjetivas humanas são rotineiramente reformadas por drogas psiquiátricas. Uma vez tendo reduzido o humano à sua dimensão corpórea, postula-se que esse mesmo corpo pode ser "tratado" como um conjunto de informações passíveis de serem decompostas, decifradas e, posteriormente, recombinadas.

Podemos ilustrar essa tendência de reduzir os condicionantes da ação humana a movimentos físico-químicos e impulsos biológicos primitivos por meio de dados empíricos que demonstram a crescente utilização de medicamentos para o tratamento de doenças que até poucas décadas atrás eram entendidas como patologias específicas à psique. Essa alteração na própria compreensão de como algumas patologias devem ser tratadas está ancorada numa crescente mudança da percepção e da representação social acerca do humano. Mas como essa 
forma de compreensão do humano, entre especialistas e leigos, ganhou tanto espaço na percepção pública? Para onde foi a subjetividade humana? Acredito que o aprofundamento de práticas médicas instrumentais, assim como o exponencial aumento no consumo de drogas farmacológicas, deve-se à reafirmação social, política e econômica de uma determinada concepção de humano que tem sido responsável por parte significativa da reelaboração do self.

Nesse sentido, o determinismo genético, a forma como a indústria farmacêutica vem deslocando a Psicanálise para um tipo de Psiquiatria, a partir da reafirmação de meros desajustes químicos do corpo e do cérebro, e o processo de medicalização da raça são manifestações de uma lógica de compreensão do humano que se sustentam na super valorização da dimensão somática dos indivíduos.

\section{Cultura Somática e a "cidadania biológica" dos selves neuroquímicos}

Trazendo essa tendência do indivíduo somático para o plano político, Rose e Novas (2003) apontam alguns aspectos relevantes que nos ajudam a refletir acerca das implicações que a construção dessa nova compreensão científica e pública sobre os indivíduos e as instituições sociais acarretam. Os autores argumentam que um novo tipo de cidadania está emergindo na era da Biomedicina, da Biotecnologia e da Genômica: uma "cidadania biológica". Tal diagnóstico é alcançado por meio da estratégia de localização da cidadania dentro de uma história política de "projetos de cidadania", desvinculando-a de um discurso político-filosófico. Essa compreensão histórica dos "projetos de cidadania" está alinhada, segundo os autores, com a visão produzida por Marshall (1992), em seu clássico ensaio de 1950, Citizenship and Social Class, a partir do qual se tornou convencional pensar a evolução da cidadania iniciando com os direitos civis durante o século XVIII, expandindo-se para a cidadania política, no século XIX, e para a cidadania social no século $X X$.

Dessa forma, projetos de cidadania representam para Rose e Novas (2003) o conjunto de práticas empregadas pelas autoridades políticas de uma nação, decorrente da forma como essas autoridades interpretam os critérios que determinam quais indivíduos pertencentes a essa nação são cidadãos em potencial. Disso, decorre, por exemplo, a forma como são definidos os indivíduos aptos a participarem das questões políticas nacionais, a imposição de um sistema legal abrangente para todo o território nacional, o estabelecimento de uma única língua nacional, de um sistema educacional único, do planejamento e da construção de determinados espaços públicos para que certas formas de pensar, sentir e agir sejam encorajadas no desenvolvimento de sistemas de segurança social etc.. 
Embora haja certa ambiguidade no texto de Rose e Novas quanto à real novidade da existência de uma cidadania biológica (pois existe um esforço analítico por parte dos autores para demonstrar como pressuposições biológicas foram importantes em diversas partes do mundo para a construção da nação), parece -me que a justificativa para anunciar o reconhecimento público e político desse tipo de cidadania decorre da preponderância que a Biologia, a Biociência, a Biomedicina e a Biotecnologia têm na construção contemporânea do que são os indivíduos, amparada numa crescente compreensão somática destes. Além disso, outro traço característico dos projetos de "cidadania biológica" é a preponderância do mercado como mola propulsora dessa construção.

\begin{abstract}
A 'biologização' da política tem sido raramente explorada a partir da perspectiva da cidadania. Histórias em torno da ideia de raça, degeneração e eugenia, e aquela da demografia e do censo, mostram como vários projetos de cidadania foram formados em termos biológicos, em termos de raça, linhas de sangue, descendência, inteligência, etc. $\mathrm{O}$ termo 'cidadania biológica' é usado para abarcar todos aqueles projetos de cidadania que têm ligado suas concepções de cidadãos às crenças sobre a existência biológica de seres humanos, como indivíduos, como família e linhagem, como comunidades, como população e raças, e como espécie. E de forma semelhante às outras dimensões da cidadania, a cidadania biológica está em transformação e re-territorialização dela mesma junto com as dimensões nacionais, locais e transnacionais. (ROSE e NOVAS, 2003, p. 2)
\end{abstract}

Na passagem do século XVIII para o XIX, argumentava Foucault, indivíduos e populações tornaram-se objetos de estratégias e cálculos do poder político, num processo por ele denominado de "estatização do biológico", produto da articulação de técnicas de disciplina do corporal com um controle biopolítico das populações, que enfatizava especialmente as noções de sexualidade, raça e degenerescência. Essa forma de biopolítica esteve historicamente vinculada à constituição e fortalecimento do Estado nacional, à afirmação da burguesia, assim como à formação de um dispositivo médico-jurídico, visando à medicalização e à normalização da sociedade (FOUCAULT, 1976; 1997; 2000). O entrelaçamento de pressuposições biológicas e projetos políticos de cidadania e de construção nacional têm sido amplamente articulados, durante séculos, sobretudo em torno da categoria de raça. 


\section{A Questão Racial: da colonização à era do Gene}

Foucault (1976) já nos chamava a atenção para o fato de que a partir do século XIX, sobretudo por meio da incorporação das tecnologias de poder sobre a espécie, tivemos a instauração de um tipo de "racismo de Estado". A eficaz utilização dessas tecnologias pelo Estado, que sustentavam esse tipo de racismo, somente foi possível a partir da reelaboração da antiga ética guerreira, que editou uma nova versão do evolucionismo e do dualismo, semelhante ao observado por Quijano (1993) no contexto da colonização das Américas.

Quijano argumenta que a ideia de raça constituiu-se num dos eixos fundamentais para a sustentação de um padrão mundial de poder que classifica socialmente todas as populações. Durante a constituição da América, por exemplo, numa fase colonial do capitalismo, estabeleceu-se, a partir de uma racionalidade eurocêntrica, uma determinada construção mental do que seriam raças. A partir do binômio raça/trabalho, supostamente baseado nas diferentes estruturas biológicas, estabeleceu-se a identidade racial como instrumento hierárquico de classificação social básica da população, a partir da qual se impôs uma sistemática divisão racial do trabalho, traduzidas na "superioridade" dos colonizadores e "inferioridade" dos colonizados. A categoria raça também foi utilização para delimitar configurações no plano político, sobretudo no tocante à construção dos Estados-nação, assim como nas transformações ligadas ao plano cultural, subjetivo e cognitivo, no que se refere à produção de novas identidades, subjetividades, intersubjetividades e de uma determinada racionalidade inerente à produção de conhecimento.

Essa versão eurocêntrica da modernidade sustenta-se a partir da articulação de dois mitos fundadores, nucleares, do eurocentrismo: a) um mito evolucionista, baseado na ideia-imagem da história da civilização humana como uma trajetória que parte de um estado de natureza, culminando na Europa, sendo seus movimentos e transformações unilineares e unidirecionais; e b) um mito dualista, que ancorou as diferenças entre não-Europa e Europa (Oriente-Ocidente, primitivocivilizado, mágico/mítico-científico, irracional-racional, tradicional-moderno, pré-capitalista-capitalista) numa diferença de natureza, sobretudo racial, e não numa história de poder. Estabeleceu-se um padrão de poder mundial (QUIJANO, 1993, p. 209-210), no qual a Europa Ocidental torna-se o centro do sistemamundo, de onde decorre o etnocentrismo dos povos europeus, que apresentava como peculiaridade o fato de ser justificado pela classificação racial da população do mundo, seguindo o modelo criado quando da colonização das Américas.

A associação entre ambos os fenômenos, o etnocentrismo colonial e a classificação racial universal, ajuda a explicar porque os europeus foram levados a sentirem-se não só superiores a todos os de- 
mais povos do mundo, mas também, em particular, naturalmente superiores - sendo que os povos colonizados eram raças inferiores.

(Quijano, 1993, p. 204)

Contudo, Quijano chama a atenção para outro tipo de dualismo que acompanharia toda a história da modernidade e que certamente coloca-se, atualmente, no centro do debate quanto às interferências genéticas, tanto por causa de sua gravitação no modo eurocêntrico de produzir conhecimento, quanto por sua estrita relação com as categorias de raça e gênero: as relações entre o corpo e o não corpo na perspectiva eurocêntrica.

A perspectiva moderna eurocêntrica incorpora a dualidade cartesiana (esta, já, uma herdeira da ambivalência não resolvida da teologia cristã medieval entre corpo e alma), convertendo essa copresença (corpo-mente) permanentemente entrelaçada em uma separação radical entre, de um lado, razão/sujeito e, de outro, corpo físico. Com isso, o corpo é "lançado" no campo dos objetos a serem percebidos, conhecidos e manipulados pela razão. Essa objetivação do corpo enquanto natureza, acoplada aos demais dualismos relacionados ao eurocentrismo, leva à concepção de que, quanto mais evoluída é a raça, mais distante do corpo, da natureza, ela se mostra. Quanto mais racional, mais próximo o sujeito encontra-se no europeu, a ser humano por excelência.

Ou seja, o racismo de Estado era legitimado, segundo Foucault (1976), na medida em que o que estava em jogo era a manutenção da vida. Dentro dessa lógica de dominação racista, ela só pode ser preservada quando é possível assegurar ao mesmo tempo, no limite, a morte dos elementos degenerados e inferiores.

Tal entendimento biológico dos seres humanos claramente relaciona-se às noções de cidadania e projetos de cidadãos tanto no nível individual quanto no nível do Estado-nação. Entretanto, essa cidadania biológica contemporânea, da qual nos falam Rose e Novas, não tem como objetivo tomar essa forma racializada e nacionalizada.

Em resumo, a cidadania foi baseada no que, do início do século XIX em diante, seria chamado de 'biologia'. Distinções dentro das nações como aqueles capazes de cidadania, e distinções entre as pessoas, como suas respectivas capacidades para regrar ou serem regradas, foram construídas sobre uma explícita ou implícita taxonomia biológica inscrita no soma dos indivíduos e da coletividade e passados através da linhagem. (ROSE e NOVAS, 2003, p. 8)

Nesse sentido, avaliam os autores, as formas de cidadania biológica contemporânea são diferentemente territorializadas - conforme nos mostram as análises 
de bioprospecção e biopirataria, nem todos temos igual cidadania nesta nova era biológica. Entretanto, as conexões entre Biologia e "humano saudável" /"humano com defeito", hoje, diferem significativamente das da era eugênica. Diferentes ideias sobre o papel da Biologia no humano "que vale a pena" são empregadas nas práticas de aborto seletivo, de diagnóstico genético pré-implantação e de seleção de embrião. Diferentes ideias sobre responsabilidades biológicas dos cidadãos são corporificadas nas normas contemporâneas de saúde e práticas de educação saudável. Diferentes práticas de cidadania podem ser vistas na crescente importância da corporalidade como práticas de identidade e nas novas tecnologias que intervêm sobre o corpo em níveis superficiais, como as cirurgias cosméticas (GILROY, 2000).

A partir de sua crítica à raciologia, Paul Gilroy sugere que as construções contemporâneas de raça orientadas-pelo-gene são muito diferentes das "antigas versões de pensar-a-raça que nós produzimos no século dezoito e dezenove". Como as relações entre os seres humanos e a natureza são transformadas pela Genômica, o significado da diferença racial é transformado, segregando a possibilidade de desafiar a maculada lógica da raciologia (GILROY, 2000, p. 15). Embora sua avaliação seja relativamente otimista, ele não perde de vista que certas pressuposições sobre a Biologia estão ligadas ao pensamento de nação, pessoa, raça, população e território do século XVIII em diante. Conforme vimos, europeus e não europeus, ou seja, tanto os sujeitos individuais e coletivos da Europa quanto os sobre os quais se exerceria a dominação europeia foram pensados em termos de sangue, linhagem, fisionomia, capacidades morais; todos esses inatos.

Segundo Waldby (2000), a maior parte dos esforços estatais não está dirigida por uma pesquisa para purificação racial, mas, sim, pela preocupação em criar um estoque hereditário específico de sua população como um recurso a ser administrado. Estão orientados pela esperança de que certas características específicas de grupos de genes de seus cidadãos possam potencialmente prover uma fonte valiosa para a geração de direitos de propriedade intelectual, para a inovação biotecnológica e a criação de biovalor. Exemplos de tal criação podem ser encontrados em recentes iniciativas da Suécia e outros países nórdicos, cujos sistemas públicos de saúde vêm estocando há anos (por vezes, há décadas) amostras de tecido humano. Originalmente motivados para viabilizar possíveis usos diagnósticos ou terapêuticos, tais bancos de tecido podem agora fornecer informações a respeito de características herdadas que podem tornar populações inteiras suscetíveis a várias doenças.

Mais do que interessados na saúde pública, os governos da Suécia e da Islândia concederam a empresas privadas a licença para operar bases de dados que entrecruzam informações genéticas extraídas dos tecidos coletados da popula- 
ção com antigos dados de censo, fichas médicas, estudos epidemiológicos e até amostras de sangue obtidas em campanhas de doação. "Nestes e em outros casos, então, o Estado tem um papel ativo em transformar seus cidadãos em uma fonte potencial para a geração de riqueza e saúde" (ROSE e NOVAS, 2003, p. 31). Para ilustrar o argumento de que um dos aspectos que diferencia a atual fase dos projetos de "cidadania biológica" num contexto biotecnológico é precisamente a preponderância que o mercado assume nesse momento, e que muito do que está em jogo é o biovalor em relação ao mercado, apresentarei a seguir formas de encaminhar essa releitura racial orientada pelas características genéticas, como é o exemplo do caso do primeiro remédio baseado na raça: o BiDil.

\section{Medicalização da Raça - O caso do medicamento BiDil}

A “"medicalização da raça” tende a suplantar a subjetividade humana, na medida em que desloca a discussão sobre etnicidade e construção de identidades, para o conceito de raça, numa suposta determinação biológica que subsume as dimensões sociais, culturais, políticas e econômicas. A compreensão desse fenômeno como uma das características da afirmação de uma compreensão somática não se dá de forma óbvia. Isso porque, apesar dos argumentos que apontam para a incompatibilidade da existência de raças como entidades biológicas, em função do baixo grau de variabilidade genética e estruturação da espécie humana (PENA, 2005; FIGUEROA, 2004), podemos observar inclusive na história recente de políticas de saúde para negros, no Brasil, uma proclamada racialização que reconhece a categoria "raça" como produto de um racismo científico, mas que pretende utilizá-la como instrumento privilegiado na luta anti-racista, como pensado pelo movimento negro norte-americano. Dentro dessa proposta de luta, propõe-se desnaturalizar a categoria "raça", enquanto conceito biológico, enfatizando seu caráter sociológico, ao apresentá-la como um constructo social, como um instrumento identitário a ser politizado em nome de uma sociedade mais justa e igualitária (MAIOR e MONTEIRO, 2005, p. 431). Contudo, apesar desse recurso do resgate da categoria raça como forma de luta social, não tem sido esse o resultado obtido na prática médica (CALVO-GONZALEZ, 2011). Para exemplificar empiricamente esse argumento, podemos observar o processo de regulamentação do remédio BiDil nos Estados Unidos.

Com base em um teste clínico, no qual pacientes com insuficiência cardíaca, autodenominaram-se negros, a FDA norte-americana (Food and Drug Administration) aprovou a comercialização da primeira droga baseada na raça: a BiDil, criada por uma pequena empresa de Biotecnologia de Massachusetts, a NitroMed. Na bula do remédio, podemos ler: 
BiDil é indicado para o tratamento de insuficiência cardíaca como um adjunto à terapia padrão em pacientes auto-identificados negros, para aumentar a sobrevida, prolongar o tempo necessário para hospitalização no caso de insuficiência cardíaca e melhorar o estado funcional relatado pelo paciente. (grifo meu) (Bula)

Contudo, ao contrário do que se pode imaginar, a droga foi originalmente desenhada sem especificação racial, e a NitroMed tinha a patente para essa droga (não específica para raça) até 2007. Entretanto, estudos clínicos iniciais não demonstraram grande eficácia e, inicialmente, o painel consultivo da FDA não aprovou sua comercialização.

No que é chamado pelo sociólogo Troy Duster (2007), ex-presidente da ASA (American Sociological Association), de "uma notável virada do destino", um dos pesquisadores da NitroMed revisou os dados e percebeu que um pequeno grupo de negros do teste clínico original havia reagido melhor ao tratamento do que o restante do grupo. Entretanto, esse mesmo teste não havia sido criado para comparar a eficácia do medicamento em grupos raciais diferentes; assim, seria necessário preparar um novo teste que validasse essa hipótese. Esse teste precisaria, ainda, ser aprovado pela FDA.

Ao invés disso, a FDA aprovou, em 2001, um teste clínico de larga escala envolvendo apenas indivíduos negros com insuficiência cardíaca. Em 2005, após uma audiência na qual um comitê consultivo da FDA recebeu os relatórios referentes a esse teste clínico - que demonstravam que o medicamento era significativamente mais eficaz que um placebo -, o BiDil foi aprovado por mais 15 anos como a primeira droga específica para raça. "Na verdade, a reivindicação de especificidade-para-raça foi o que tornou a droga patenteável" (DUSTER, 2007, p. 703).

De acordo com Duster, a utilização exclusiva de participantes negros nesse teste clínico do BiDil indica três pressupostos problemáticos a respeito de raça e medicina. Primeiro, a afirmação de que negros apresentam um maior risco de desenvolver insuficiência cardíaca do que outros grupos étnicos. O fato é que os dados apresentados pela NitroMed para embasar essa afirmação constam de fontes de há mais de vinte anos. A diferença de mortalidade citada nestes trabalhos era de 2 negros para 1 branco, taxa que caiu de 1,2 para 1 em 2005 (KAHN, 2005). Segundo, sobre o BiDil ter mais efeito na população negra: não foi desenhado ou realizado nenhum teste clínico específico para testar essa hipótese; ao contrário, o teste em larga escala concentrou-se em negros, não oferecendo parâmetros substantivos de comparação. E, terceiro, deve-se observar que foi apresentado pela NitroMed um conjunto de dados demonstrando disparidades de mortalida- 
de entre as raças (negros e brancos) em faixas comuns de idade. Ao que tudo indica, os dados são verdadeiros. Entretanto, focalizam a faixa entre 45 e 64 anos de idade, na qual se concentram apenas pouco menos de $6 \%$ do total de mortes por insuficiência cardíaca. Se tomarmos a faixa acima dos 65 anos de idade (correspondente a aproximadamente $93,7 \%$ das mortes), a diferença desaparece.

Algumas análises afirmam que o "racismo científico" aparente neste caso diz mais respeito ao mercado do que a concepções morais ou éticas. O aspecto importante a ser considerado aqui seria a busca pela maximização dos lucros por parte da NitroMed. Kahn (2005) lembra que a patente do BiDil, considerado como uma droga sem especificidade-por-raça, expiraria em 2007 e, agora, sua patente vale até 2020, como droga específica-para-raça. Esses 13 anos de proteção a mais são motivo comercial suficiente para explicar a tentativa da empresa em apresentar o BiDil como droga racial, mesmo sem suficiente evidência médica.

Mas esse mesmo autor afirma que a dimensão comercial, ainda que importante para entendermos o caso, não é exclusiva. Ainda que possa ser possível usar a raça para perceber disparidades nos serviços públicos de saúde, a aprovação do BiDil manda a mensagem de que, na medida em que há disparidades, a solução é mudar as moléculas, não as causas das diferenças. Dessa maneira, o "racismo científico" estimulado pela divulgação da existência de uma droga com essas características torna-se um fato político:

\footnotetext{
O que está em funcionamento aqui é uma apropriação da raça, reificada no caso do BiDil, para servir a agendas políticas mais amplas visando transmutar disparidades de saúde enraizadas em desigualdades econômicas e sociais, em meras diferenças de saúde enraizadas na biologia e na genética (KAHN, 2005, p. 656).
}

Devemos nos lembrar que o BiDil não foi desenhado para uma raça específica. O medicamento é simplesmente uma combinação de dois princípios ativos já existentes, não age seletivamente sobre indivíduos que apresentam um suposto "genótipo característico dos negros". Entretanto, ao ser alardeado como "a primeira droga específica-para-raça" ou (como se lê no título da home page do medicamento) "Prescription Drug for African Americans with Heart Disease", os resultados de pesquisas são "simplificados" e apropriados pela mídia, estimulando afirmações (falsas) que enfatizam diferenças genéticas entre populações e, finalmente, raças. "A aprovação do BiDil para uso apenas por negros encoraja uma maior racialização da farmacologia e promove a visão de que as diferenças raciais na saúde são atribuíveis a causas biológicas" (DUSTER, 2007, p. 703). 
Reflexões finais: para além do indivíduo somático e do biovalor da "cidadania"

Esse mecanismo de transformação da vida em biovalor, conforme avalia Waldby (2000), passa precisamente pelo artifício do mercado em trabalhar com a retórica de que a vida pode ser resumida como um complexo de informações. Na medida em que a política começa a atuar sobre mais qualidades "vitais", ou como dizia Foucault, com o objetivo do "fazer viver", e em que a própria vida, sua matéria biológica, passa a possuir tanto um significado social quanto capitalista, a vitalidade de cada um de nós, assim como da coletividade, torna-se uma fonte potencial de biovalor.

No tipo de estatização descrito pela lógica biopolítica, proposta por Foucault, o Estado dedica-se a gestar aspectos da vida social (tais como: saneamento básico, cuidados médicos, controle de natalidade e óbitos etc.), o que acaba por constituir os serviços nacionais de saúde pública. Conforme nos observa Rose e Novas (2003. p. 29), num contexto mais liberal, é evidente que também "empreendimentos privados tiveram um papel importante na produção de comida, nos serviços e na produção de produtos farmacêuticos que simultaneamente gerariam lucros privados e bens públicos", gerando um "mercado de saúde". Contudo, esse mercado que se constitui majoritariamente no século XX, sob a regulamentação do Estado, sobretudo no que tange a comercialização e produção de alimentos e produtos farmacêuticos, passa por uma profunda transformação, remodelando aspectos cruciais da economia política, da própria acumulação de riqueza que se cristaliza através de um biovalor, impulsionado pela genética e pelas neurociências, que se manifesta por meio de reconfigurações nas relações entre os aparatos do Estado, o conhecimento científico e médico, as atividades de empresas comerciais.

Os autores argumentam que podemos analisar três dimensões do biovalor: primeiramente, na forma como a vida torna-se produtora de valor econômico; segundo, pela compreensão coletiva de que a manipulação da vida gera um valor que se sustenta pelo melhoramento da saúde, e, terceiro, que a produção tanto de riqueza quanto de saúde está entrelaçada por valores éticos. Essa produção de "biovalor e geração de riqueza" ocorre, sobretudo, por meio da aplicação da tecnociência ao corpo, ao nível molecular, tornando-o inteligível, calculável, visível e manipulável e passível de intervenção em seu nível biológico mais básico, de tal forma que cada corpo humano torna-se um banco de reservas potenciais para a geração de biovalor.

Em que pese a força estruturante de ações estatais e mercadológicas baseadas numa tecnociencia sustentada por uma lógica de afirmação de uma individualidade somática, quando observamos a forma como essas práticas são traduzidas 
e incorporadas na vida cotidiana, notamos que estas permanecem também orientadas pelo crivo da subjetividade. Apesar do projeto biopolítico que age no sentido de produzir afetos e comportamentos desejados/dóceis, de reafirmar a existência científica de distinções raciais, de corroborar a modificação genética de alimentos, seria limitado não reconhecer os movimentos conscientes (ou não) de resistência e ressignificação social que surgem a partir das dinâmicas entre as estruturas sociais e o mundo da vida, que também se expressa através da proliferação de estilos de vida alternativos, que se contrapõem a um tipo de produção sócio-ambiental insustentável e que reafirma, confronta e reelabora o conhecimento mais hightech à luz do saberes locais e tradicionais - repensando suas estratégias alimentares e hábitos medicinais, por exemplo.

\section{Referências Bibliográficas}

BECK, U. Risk Society - Towards a New Modernity. London: Sage Publications, 1992 (1a edição de 1986).

CALVO-GONZALEZ, H. "Construindo corpos nas consultas médicas: uma etnografia sobre hipertensão arterial em Salvador, Bahia". Caderno $C R H$, Salvador, v. 24, n. 61, 2011, p.81-96.

DUSTER, T. “Medicalisation of Race”. Lancet, 369, 2007.

FIGUEROA, A. "Contextualização conceitual e histórica". Seminário Nacional de Saúde da População Negra. Caderno de textos básicos. Brasília: Seppir, Ministério da Saúde, 2004.

FOUCAULT, M. The Birth of Clinic: An archeology of medical perception. London: Tavistoc, 1973.

. La Volonté de Savoir. Paris: Gallimard, 1976.

. Microfísica do Poder. Rio de Janeiro: Edições Graal, 1979.

. Resumo dos cursos do Collège de France (1970-1982). Rio de Janeiro: Jorge Zahar Editor, 1997.

. Em Defesa da Sociedade. São Paulo: Martins Fontes, 2000.

GILROY, P. Between Camps: Race, identity and nationalism at the end of the colour line. London: Allen Lane, 2000.

HABERMAS, J. O Futuro da Natureza Humana: a caminho de uma eugenia liberal? São Paulo: Martins Fontes, 2004. 
HEATH, D.; RAPP, R.; TAUSSIG, Karen-Sue. "Genetic Citizenship". In: Nugent, D.; Vincent, J. (eds.) Companion to the Handbook of Political Anthropology. London: Blackwells, 2003. JASANOFF, S. Designs on Nature: science and democracy in Europe and United States. Princeton: Princeton University Press, 2005.

KAHN, J. "Misreading race and genomics after BiDil". Nature Genetics, 37(7), 2005.

MAIOR, M. C.; Monteiro, S. "Tempos de racialização: o caso da 'saúde da população negra' no Brasil. História, Ciência, Saúde - Manguinhos, v.12, n.2, 2005.

MARSHALL, T. "Citizsenship and Social Class". In: Marshall, T. H.; Bottomore, T. Citizenship and Social Class. London et altera: Pluto Press, 1992 (1a edição de 1950)

MONTEIRO, M. Dilemas do Humano: reconstruindo o corpo numa era (bio)tecnológica. Campinas: Tese de Doutorado,UNICAMP, 2005.

MOSS, L. What Genes Can't do?. Cambridge, Mass.: MIT Press, 2003.

PENA, S. D. J. "Razões para banir o conceito de raça da medicina brasileira”. História, Ciências, Saúde - Manguinhos. V.12, n.1, 2005.

QUIJANO, A. "Colonialidad del Poder, Eurocentrismo y América Latina”. In: Lander, E. (comp.) La Colonialidad del Saber: eurocentrismo y ciencias sociales. Perspectivas latinoamericanas. RA: CLACSO, 1993.

RABINOW, P. "Artificiality and enlightenment: from sociobiology to biosociality". In Crary, J.; Kwinter, S. (orgs.) Incorporations. New York: Zone Books, 1992.

. "Cortando as amarras: fragmentação e dignidade na modernidade hoje". Revista Brasileira de Ciências Sociais, vol. 8, n. 23, 1993.

. Making PCR: A story of Biotechnology. Chicago: University of Chicago Press, 1996.

. French DNA: Trouble in Purgatory. Chicago: The University of Chicago

Press, 1999.

ROSE, N. Inventing our Selves. Psychology, Power and Personhood. Cambridge: Cambridge University Press, 1998.

. Powers of Freedom. Reframing Political Thought. Cambridge: Cambridge University Press, 1999. 
. "The Politics of Life Itself". Theory, Culture and Society, vol. 18, n. 16, dez. 2001.

. “Neurochemical Selves". Society, 41, 1, nov-dez, 2003, pp. 46-59.

ROSE, N.; NOVAS, C. "Biological Citizenship". In Ong, A.; Collier, S. (eds.). Blackwell Companion to Global Anthropology. Oxford: Blackwell, 2003.

ROUDINESCO, E. Em defesa da psicanálise. Editora Zahar, 2009.

SANTOS, L. G. Politizar as novas tecnologias - o impacto sócio-técnico da informação digital e genética. São Paulo: Editora 34, 2003.

WALDBY, C. "The Body and the Digital Archive: the Visible Human Project and the computerisation of medicine". Health: as Interdisciplinary Journal for the Social Study of Health, Illness and Medicine, vol 1, n 2, 1997.

The Visible Human Project: informatic bodies and posthuman medicine. London: Routledge, 2000. 